\section{Microbial characteristics of Conciato Romano: an artisanal cheese made from raw sheep's milk}

\author{
Amalia Mormile, Luigi Scarano, \\ Andrea Ariano, Nicoletta Murru, \\ Lucia Vollano, Aniello Anastasio \\ Dipartimento di Medicina Veterinaria \\ e Produzioni Animali, Università degli \\ Studi di Napoli Federico II, Napoli, Italy
}

\section{Abstract}

The aim of this study was to assess the microbial characteristics of a batch of Conciato Romano during manufacturing and ripening. Conciato Romano is a traditional cheese made from raw sheep's milk without starter cultures in the province of Caserta (Southern Italy) using traditional methods. A total of 7 samples (raw milk, curd and cheese wheels taken after $25,60,120$ and 180 days of ripening) were screened for hygiene indicators microorganisms counts (total viable count, Enterobacteriaceae, total coliforms, E. coli, clostridia sulphite reducing, yeasts, coagulasepositive staphylococci, enterococci), for autochthonous lactic acid flora counts (mesophilic and thermophilic lactococci and lattobacilli), and also for Salmonella spp. and Listeria monocytogenes presence. In raw milk, low values were detected for total aerobic flora (3.2 log $\mathrm{cfu} / \mathrm{mL})$, Enterobacteriaceae and total coliforms ( $2 \mathrm{cfu} / \mathrm{mL})$, and the autochthonous starter lactic flora was predominant (3.2 log $\mathrm{cfu} / \mathrm{mL})$. During ripening, total aerobic flora was constant $\left(10^{7}-10^{8} \mathrm{cfu} / \mathrm{g}\right)$; total coliforms, $E$. coli, Enterobacteriaceae and yeasts were not detected starting from the $60^{\text {th }}$ day of ripening. Enterococci ranged from 4.2 to $6.2 \mathrm{log} \mathrm{cfu} / \mathrm{g}$. The mesophilic lactic flora was dominant with values always $>6 \log$ cfu/g during the whole ripening period. Pathogens were never detected. The results of this study highlighted how the raw milk indigenous lactic flora, the traditional production techniques and the cheesemaker's experience are essential to guarantee the unique nature of Conciato Romano.

\section{Introduction}

Conciato Romano is an artisanal cheese produced in the province of Caserta, Southern Italy. The technique of aging it in clay jars probably dates back to Samnite civilisation. The traditional process of production involves the use of raw sheep milk without starter cultures, so the maturation of cheese is a direct consequence of the metabolic activity of the lactic flora coming from the environment and milk whose organoleptic properties are influenced by the aromatic plants of the mountains around Caserta where the sheep graze (Buchin et al., 1999). The microbial ecology of artisanal cheeses widely affects the production process and its quality. The study of the microbiological characteristics of these cheeses is fundamental in order to improve their quality in accordance with current legislation and to preserve, at the same time, the microbial biodiversity and their characteristic nature. Therefore, the purpose of this study was to evaluate the microbial ecology of Conciato Romano during production and ripening.

\section{Materials and Methods}

The experiment began in February 2012 at the Le Campestre farm located in the municipality of Castel di Sasso, Caserta Province, Southern Italy. In accordance with the traditional methods used in the area and the production capacity of small processing dairy farm, one batch of cheese was made by transforming about $10 \mathrm{~L}$ of raw milk derived exclusively from the morning milking of about 50 sheep of different breeds (mainly meat breeds). The milk was transported in a plastic container to the production laboratory where was processed in 15 min. In accordance with the unusual production methods characterised by the use of a tanning made from olive oil, casavecchia wine, chili and piperna. At the end of processing, the batch of cheese was left to season for six months in earthenware closed jars that were rotated every ten days to allow a uniform distribution of tanning.

A total of 7 samples was collected and transported at $4^{\circ} \mathrm{C}$ to the Laboratory of Food Microbiology, Department of Veterinary Medicine, University Federico II, Naples, Italy, and directly used for evaluation of bacterial populations. In particular, the sampling plan provided the analysis of bulk milk (L) and the curd (C) on the day of production, the primosale (i.e. fresh, lightly salted cheese) $24 \mathrm{~h}$ after production (Cf 0 ), 1 cheese wheel after 25 days of drying (Cf 1 ) and 3 cheese wheels after 60 (Cf 2), 120 (Cf 3) and 180 (Cf 4) days of ripening respectively.

Ten-fold serial dilutions in Ringer's solution were prepared for the microbiological analysis from which inocula of 0.1 and $1 \mathrm{~mL}$ were seeded in order to enumerate total viable count (TVC) at $30^{\circ} \mathrm{C}$ (NF EN ISO 4833:2003; ISO, 2003): the group of hygiene indicators germs as total coliforms (ISO 4832:2006; ISO, 2006), E. coli (ISO 16649-2:2001; ISO, 2001a), Enterobacteriaceae (ISO 21528-2:2004; ISO,
Correspondence: Amalia Mormile, Dipartimento di Medicina Veterinaria e Produzioni Animali, Università degli Studi di Napoli Federico II, via F. Delpino 1, 80137 Napoli, Italy.

Tel. +39.081.2536084 - Fax: +39.081 .458683 .

E-mail: amalia.mormile@gmail.com

Key words: Artisanal cheese, Microbiological diversity, Raw sheep's milk.

Conflict of interests: the authors declare no potential conflict of interests.

Acknowledgments: the work was carried out thanks to the project IZSM Prodotti Agroalimentari Tradizionali della Regione Campania.

Received for publication: 27 May 2013. Revision received: 6 August 2013.

Accepted for publication: 9 August 2013.

This work is licensed under a Creative Commons Attribution 3.0 License (by-nc 3.0).

(C) Copyright A. Mormile et al., 2013

Licensee PAGEPress, Italy

Italian Journal of Food Safety 2013; 2:e46

doi:10.4081/ijfs.2013.e46

2004a), coagulase-positive staphylococci (NF EN ISO 6888-1/A1:2004; IS0, 2004b), yeasts on rose-bengal chloramphenicol agar containing chloramphenicol supplement (Oxoid) at $22^{\circ} \mathrm{C}$ for 5 days, sulphite-reducing clostridia on SPS Agar (Oxoid) at $43^{\circ} \mathrm{C}$ for $24 \mathrm{~h}$, enterococci on Kanamycin Easculin Azide Agar Base (Oxoid) + Kanamycin Selective Supplement (Oxoid) at $37^{\circ} \mathrm{C}$ for $24-48 \mathrm{~h}$, the autochthonous lactic acid bacteria such as mesophilic and thermophilic lactococci (Mlc; Tlc) on M17 Agar (Oxoid) at 30 and $42^{\circ} \mathrm{C}$ respectively for $72 \mathrm{~h}$ under anaerobic conditions, and mesophilic and thermophilic lactobacilli (Mlb;Tlb) on Rogosa agar (Oxoid) at $30^{\circ} \mathrm{C}$ for 5 days and $42^{\circ} \mathrm{C}$ for $72 \mathrm{~h}$ respectively under anaerobic conditions $\left(\begin{array}{lll}5 \% & \mathrm{CO}_{2}\end{array}\right)$. Finally, each sample was screened for the presence of Salmonella spp. (ISO 6785:2001 IDF 93:2001; ISO, 2001b) and Listeria monocytogenes (IS0 11290-1:1996; IS0, 1996). All analyses were performed in duplicate, and the mean value of each count was expressed in Log cfu/mL-g.

\section{Results}

The counts of TVC at $30^{\circ} \mathrm{C}$, Enterobacteriaceae, total coliforms, E. coli, clostridia sulphite reducing, yeasts, enterococci and lactic flora in milk and cheese are shown in Figures 1 and 2.

In raw milk, TVC at $30^{\circ} \mathrm{C}$ was $3.2 \log \mathrm{cfu} / \mathrm{mL}$ and in cheese it ranged from 6.5 to $8.5 \log$ 
$\mathrm{cfu} / \mathrm{g}$. Enterobacteriaceae and total coliforms, from loads lower than $2 \log \mathrm{cfu} / \mathrm{mL}$ in raw milk, reached $6 \log \mathrm{cfu} / \mathrm{g}$ in primosale, then decreased until becoming undetectable from the $60^{\text {th }}$ ripening day. $E$. coli was not detected in raw milk and in cheese showed the same performance of total coliforms but with values lower than $1 \log \mathrm{cfu} / \mathrm{g}$. Yeasts were detected only in C, primosale e Cf1 samples with loads of 4.8, 6.1 and $5.6 \log \mathrm{cfu} / \mathrm{g}$, respectively (Figure 1). Clostridia sulphite reducing and coagulase positive were never detected.

Enterococci were absent in raw milk while in cheese they reached a maximum of $7 \mathrm{log}$ cfu/g 25 days after production, then ranged from 5 to $6.2 \log \mathrm{cfu} / \mathrm{g}$ up to 120 days and were absent from the $180^{\text {th }}$ ripening day on. Mesophilic lactobacilli (Mlb), were not revealed in raw milk, while in cheese they reached $7.5 \mathrm{log} \mathrm{cfu} / \mathrm{g}$ after 60 ripening days and then always demonstrated values above $6 \log \mathrm{cfu} / \mathrm{g}$ up to the end. Termophilic lactobacilli (Tlb) were present only in $\mathrm{C}$ and the cheese sample examined on the $60^{\text {th }}$ ripening day with values of 1.2 e $7 \log \mathrm{cfu} / \mathrm{g}$, respectively (Figure 2).

Mesophilic and termophilic lactococci (Mlc; Tlc) had the same values of $3.2 \mathrm{log} \mathrm{cfu} / \mathrm{g}$ in raw milk which, on the contrary, showed a different trend during production and ripening; Mlc reached $8.4 \log \mathrm{cfu} / \mathrm{g}$ after 25 days from production and then always showed values above $6.2 \log$ $\mathrm{cfu} / \mathrm{g}$ until the end. Tlc showed a maximum of $6.3 \mathrm{log} \mathrm{cfu} / \mathrm{g}$ in $\mathrm{C}$, then decreased and was absent from $120^{\text {th }}$ ripening day (Figure 2). Listeria monocytogenes and Salmonella spp. were never detected.

\section{Discussion}

This work studied the microbial ecology of Conciato Romano cheese for the first time. The raw milk flora was made from total viable count levels conforming to limits established by European Regulation regarding milk of different species from that vaccine intended for the production of raw milk products (All . III, sect. IX of EC Regulation 2004/853; European Commission, 2004), a small number of Enterobacteriaceae and total coliforms and a predominant indigenous starter lactic flora (Mlc and Tlc).

As in other pecorino cheeses (Gerasi et al., 2003; Pisano et al., 2006) total coliforms, E. coli, Enterobacteriaceae were absent from the $60^{\text {th }}$ day of ripening. The same can be said for yeasts; these are part of the secondary or residual flora of ripened cheeses (Corbo et al., 2001) and only in some cheeses their presence on the crust play an important role in the maturation of the product.

A key role in the maturation of Conciato Romano could be performed by the metabolic activity of lactic acid bacteria: the flora of this cheese was dominated by mesophilic lactococci and lactobacilli. Mlc predominated in the first 25 days after production carrying out the acidification of the product. From the initial phase of ripening, Mlc decreased by about 1 log and non starter lactic flora (Mlb) predominated with values never below 6 log cfu/g until the end as reported by Coda et al. (2006) who studied various Italian sheep's cheeses. The non-starter lactic acid bacteria, although normally present in low numbers in milk, become the distinctive element of lactic flora of the ripened cheeses due to their ability to grow in particularly hostile environments characterised by high salt concentrations, low temperatures, low concentrations of fermentable carbohydrates, acid $\mathrm{pH}$, low $\mathrm{a}_{\mathrm{w}}$ and by the presence of bacteriocins. These microorganisms, being also widespread in the processing environments, are often isolated from artisanal dairy productions (Macedo et al., 1995; Pedonese et al., 2002). As described in numerous studies on cheeses made from raw sheep's and goat's milk (Macedo et al., 2004; Medina et al., 1992; Psoni et al., 2003), enterococci were present with values of between 4.2 and $7 \log$ cfu/g up to 120 days of ripening (Figure 2).

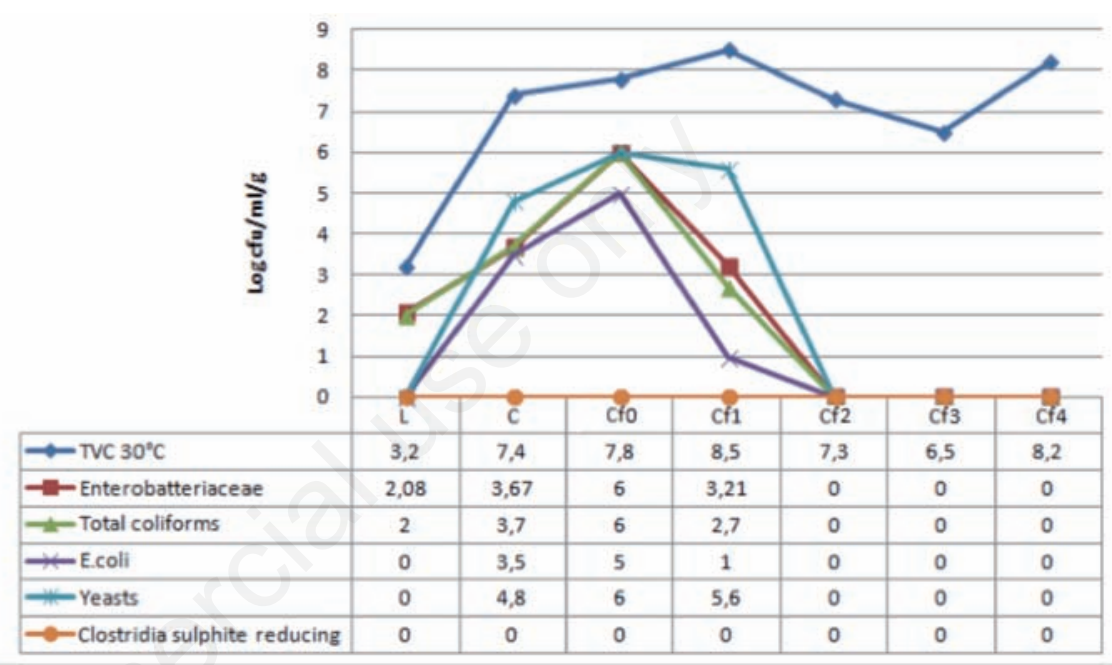

Figure 1. Performance of total viable count (TVC) at $30^{\circ} \mathrm{C}$, Enterobacteriaceae, total coliforms, $E$. coli, yeasts and Clostridia sulphite reeducing in bulk milk (L), curd (C), primosale (i.e. fresh, lightly salted cheese) (Cf 0 ), cheese wheels after 25 drying days (Cf 1 ) and 60 (Cf 2), 120 (Cf 3), 180 (Cf 4) ripening days.

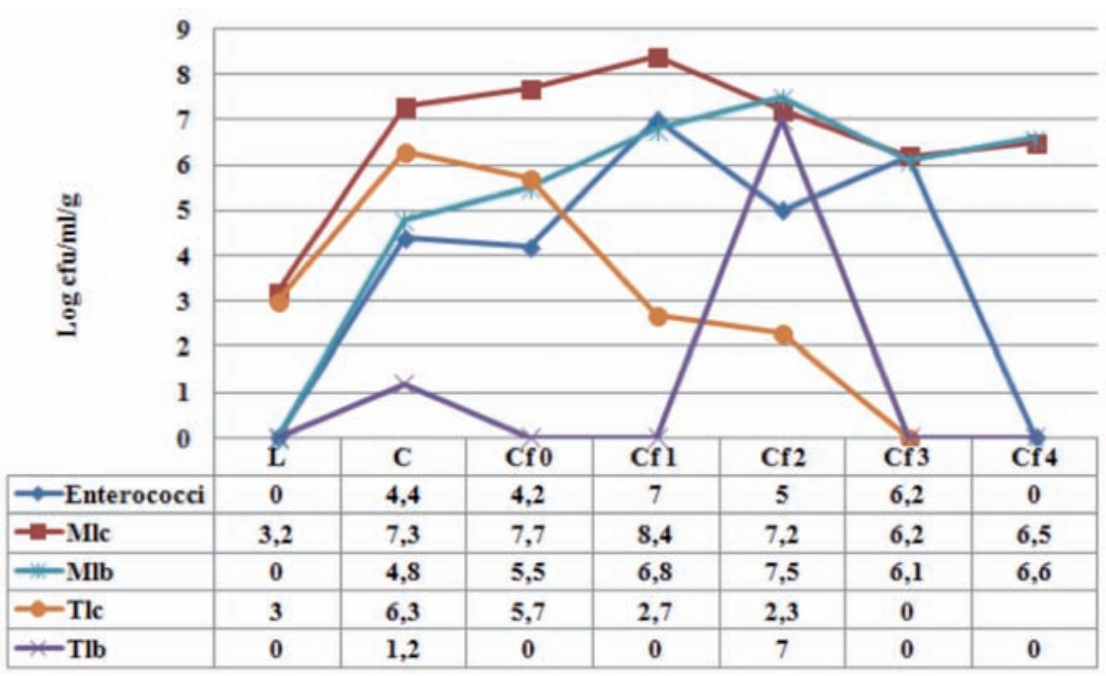

Figure 2. Performance of mesophilic and termophilic lactococci (Mlc; Tlc), mesohpilic and termophilic lactobacilli (Mlb; Tlb), and enterococci in bulk milk (L), curd (C), primosale (i.e. fresh, lightly salted cheese) (Cf 0 ), cheese wheels after 25 drying days (Cf 1 ) and 60 (Cf 2), 120 (Cf 3), 180 (Cf 4) ripening days. 
Enterococci certainly were shown to be an important part of Conciato Romano flora because they are now recognised by several authors (Cenci Goga and Di Antonio, 1995; Giraffa et al., 1997; Mormile et al., 2012) as microorganisms characterised by an important starter and non-starter activity.

\section{Conclusions}

This survey was conducted to define the evolution of the microflora of Conciato Romano in order to examine its health quality by means of objective criteria. The present study certainly highlighted how Conciato Romano is an artisanal cheese characterised by unique organoleptic characteristics and good sanitary qualities at the same time. It is therefore desirable to promote the development of such artisanal products from Campania which, despite being small scale, are unique.

\section{References}

Buchin S, Martin B, Dupont D, Bornard A, Achilleos C, 1999. Influence of the composition of Alpine highland pasture on the chemical, rheological and sensory properties of cheese. J Dairy Res 579:588-666.

Cenci Goga BT, Di Antonio, 1995. Behaviour of lactic and non lactic microflora during the production and ripening of farm-manufactured Pecorino cheese (Umbria). Ann. Microbiol. Enzim. 45:219-35.

Coda R, Brechany E, De Angelis M, De Candia S, Di Cagno R, Gobbetti M, 2006. Comparison of the compositional, microbiological, biochemical, and volatile profile characteristics of nine Italian ewes' milk cheeses. J Dairy Sci 4126:43-89.

Corbo MR, Lanciotti R, Albenzio M, Sinigaglia M, 2001. Microbiology Occurrence and characterization of yeasts isolated from milks and dairy products of Apulia region. Int J Food Microbiol 147:152-69.
European Commission, 2004. Regulation of the European Parliament and of the Council of 29 April 2004 laying down specific hygiene rules for on the hygiene of foodstuffs, 853/2004/CE. In: Official Journal, L 139/55, 30/04/2004.

Gerasi E, Litopoulou-Tzanetaki E, Tzanetakis N, 2003. Microbiological study of Manura, a hard cheese made from raw ovine milk in the Greek island Sifnos. Int J Dairy Technol 117:122-32.

Giraffa G, Carminati D, Neviani E, 1997. Enterococci isolated from dairy products: a review of risks and potential technological use. J Food Protect 732:737-60.

IS0, 1996. Microbiology of food and animal feeding stuffs. Horizontal method for the detection and enumeration of Listeria monocytogenes. Part 1: detection method. IS0 Norm 11290-1:1996. International Standard Organization ed., Geneva, Switzerland.

ISO, 2001a. Microbiology of food and animal feeding stuffs. Horizontal method for the enumeration of beta-glucuronidase-positive Escherichia coli. Part 2: colony-count technique at 44 degrees $\mathrm{C}$ using 5-bromo4-chloro-3-indolyl beta-D-glucuronide. ISO Norm 16649-2:2001. International Standard Organization ed., Geneva, Switzerland.

ISO, 2001b. Milk and milk products Detection of Salmonella spp. ISO Norm 6785:2001 IDF 93:2001. International Standard Organization ed., Geneva, Switzerland.

ISO, 2003. Microbiology of food and animal feeding stuffs. Horizontal method for the enumeration of microorganisms. Colonycount technique at 30 degrees $\mathrm{C}$. ISO Norm 4833:2003. International Standard Organization ed., Geneva, Switzerland.

ISO, 2004a. Microbiology of food and animal feeding stuffs. Horizontal methods for the detection and enumeration of Enterobacteriaceae. Part 2: colony-count method. ISO Norm 21528-2:2004. International Standard Organization ed., Geneva, Switzerland.

ISO, 2004b. Microbiology of food and animal feeding stuffs. Horizontal method for the enumeration of coagulase-positive staphylococci (Staphylococcus aureus and other species). Part 1: technique using BairdParker agar medium - amendment 1: inclusion of precision data (ISO 68881:1999/Amd 1:2003). ISO Norm 215282:2004. International Standard Organization ed., Geneva, Switzerland.

ISO, 2006. Microbiology of food and animal feeding stuffs. Horizontal method for the enumeration of coliforms. Colony-count technique. ISO Norm 4832:2006. International Standard Organization ed., Geneva, Switzerland.

Macedo AC, Malcata FX, Hogg TA, 1995. Microbiological profile in Serra ewes' cheese. J Appl Microbiol 1:11-79.

Macedo AC, Tania G, Tavares A, Malcata FX, 2004. Influence of native lactic acid bacteria on the microbiological, biochemical and sensory profiles of Serra da Estrela cheese. Food Microbiol 233:240-1.

Medina M, Gaya P, Nuñez M, 1992. Gredos goats' milk cheese: microbiological and chemical changes throughout ripening. J Dairy Res 563:566-9.

Mormile A, Barile M, Murru N, Björkroth J, 2012. [Caratterizzazione della flora lattica autoctona di un formaggio campano al peperoncino prodotto da latte crudo di pecora]. [Article in Italian]. Ital J Food Safety 77:80-1.

Pisano MB, Fadda ME, Deplano M, Corda A, Cosentino S, 2006. Microbiological and chemical characterization of Fiore Sardo, a traditional Sardinian cheese made from ewe's milk. Int J Dairy Technol 171:179-89.

Pedonese F, Innocenti E, Nuvoloni R, D’Ascenzi C, Rindi S, Cerri D, Giraffa G, Neviani E, 2002. Characterization of autochthonous microflora of the traditional ovine cheese Pecorino del Parco di Migliarino - San Rossore [Tuscany]. Scienza e Tecnica Lattiero Casearia 53:213-34.

Psoni L, Tzanetakis N, Litopoulou-Tzanetaki E, 2003. Microbiological characteristics of Batzos, a traditional Greekcheese from raw goat's milk. Food Microbiol 575:582620 . 